\title{
NOTES
}

\section{Improved Description of the Cell Wall Architecture of the Xylanolytic Eubacterium Clostridium xylanolyticum}

\author{
GREG M. ROGERS ${ }^{1}$ AND PAUL MESSNER ${ }^{2 *}$
}

Department of Microbiology, University of the Witwatersrand, Johannesburg 2000, South Africa, ${ }^{1}$ and Zentrum für Ultrastrukturforschung und Ludwig-Boltzmann-Institut für Molekulare Nanotechnologie, Universität für Bodenkultur, A-1180 Vienna, Austria ${ }^{2}$

The complex cell envelope profile of the anaerobic, spore-forming, xylanolytic eubacterium Clostridium xylanolyticum ATCC 49623 (G. M. Rogers and A. A. W. Baecker, Int. J. Syst. Bacteriol. 41:140-143, 1991) was investigated in greater detail. Although growing cells of this organism produced a gram-negative staining reaction, electron microscopy of thin sections of cells clearly revealed a gram-positive cell envelope profile. The cell wall consists of a thin peptidoglycan layer with a regularly arranged surface layer outside it. Older cells in the stationary phase may have surface layers on both sides of the peptidoglycan, providing a multilayer thin-section profile. Freeze-etched preparations of whole cells revealed an oblique surface layer lattice $(a=6.6 \mathrm{~nm} ; b=5.3$ $\mathrm{nm} ; \boldsymbol{\gamma} \sim 7^{\circ}$ ). The results of sodium dodecyl sulfate-polyacrylamide gel electrophoresis of a solubilized whole-cell extract indicated that the molecular mass of the surface layer monomer was approximately $180 \mathrm{kDa}$. Treatment of the gels with periodic acid-Schiff reagent resulted in a weak, but unambiguously positive staining reaction. Our data indicate that a glycosylated surface layer protein is present on the cell surface of $C$. $x y l a n o l y t i c u m$.

Biological hydrolysis of hemicelluloses is of considerable interest in forestry and the pulp and paper industry. As a result of a biopulping research program in South Africa, the obligatory anaerobic eubacterium Clostridium xylanolyticum was isolated from Pinus patula wood chips (8).
The results of light microscopic characterization (spore formation) of an isolate and DNA-DNA hybridization experiments led to taxonomic classification of this organism as a novel Clostridium species (8). However, Gram-staining results and the unusual five-layer cell envelope profile ob-
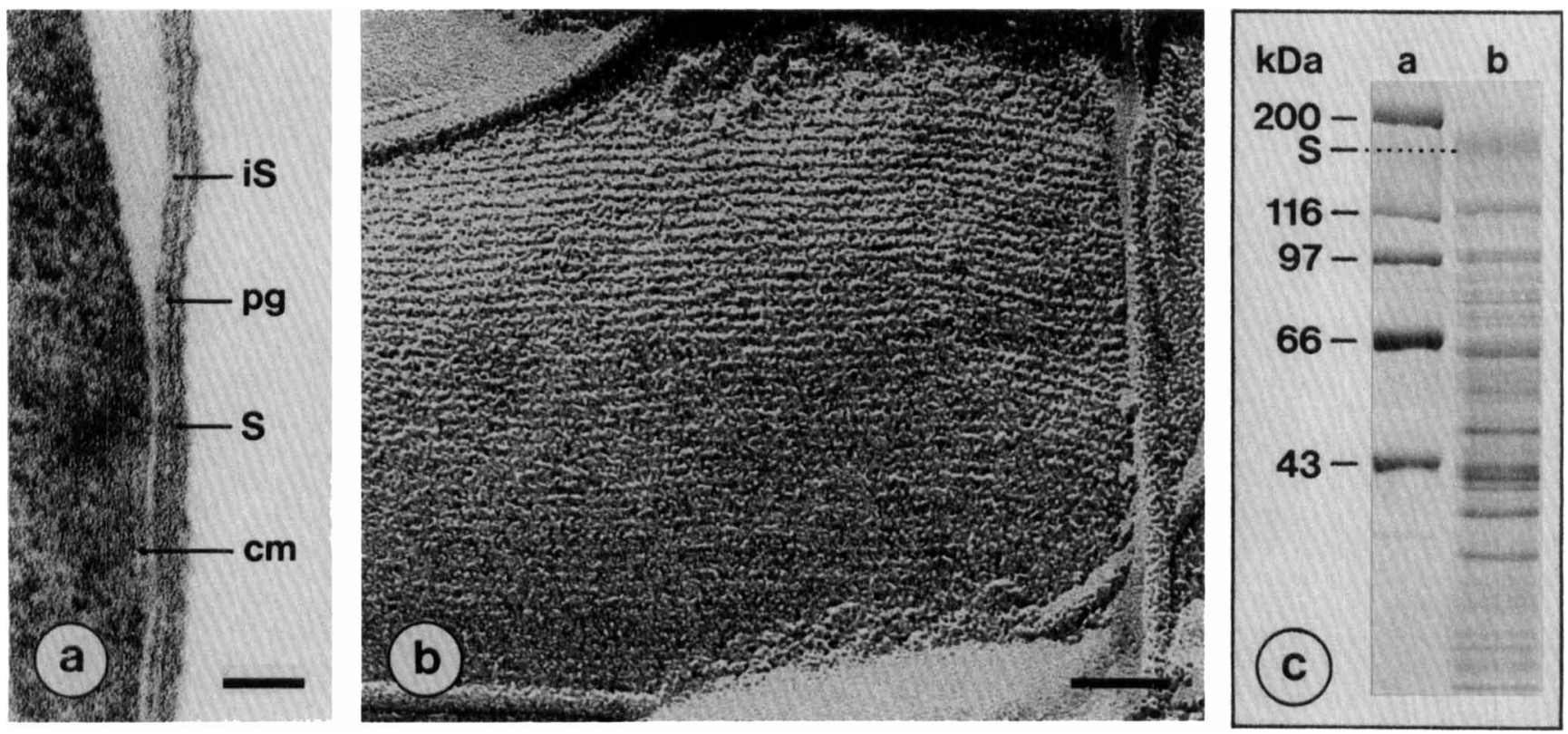

FIG. 1. (a) Electron micrograph of a thin section of a C. xylanolyticum cell. A second, artificial S layer (iS) is formed on the inner surface of the peptidoglycan layer (pg). The three-layer wall structure is visible where the cell wall is detached from the peptidoglycan. S, S layer; $\mathrm{cm}$, cytoplasmic membrane. Bar $=50 \mathrm{~nm}$. (b) Freeze-etched and metal-shadowed preparation of intact cells, revealing the regular S-layer lattice and flagella. Bar $=50 \mathrm{~nm}$. (c) Sodium dodecyl sulfate-polyacrylamide gel electrophoresis of sodium dodecyl sulfate-solubilized whole cells stained with Coomassie blue. The positions of molecular mass standards are indicated on the left.

\footnotetext{
* Corresponding author.
} 
served (8) apparently contradict this conclusion. The divergent observations described above prompted us to investigate the cell envelope profile of $C$. xylanolyticum in greater detail.

Ultrastructural characterizations of many bacteria have shown that their Gram-staining reactions are determined by their cell wall architecture (1-3). Thus, it is not surprising that gram-positive bacteria that have a thin peptidoglycan layer, like several Clostridium species (4), do not retain the staining reagent and tend to produce a "misleading" Gram reaction (1). Thin sections of $C$. xylanolyticum (Fig. 1a) show the typical gram-positive cell envelope profile and no outer membrane. Interestingly, a regularly arranged surface layer (S layer) $(7,9,11)$ is present as the outermost envelope component. The initial description of $C$. xylanolyticum (8) should have included the statement that the cell wall profile reveals a thin peptidoglycan layer with a regularly arranged S layer outside it. Sleytr and Glauert (10) have reported that cells in the late stationary phase or autolyzed cells can form a second layer from excess S-layer material on the inner side of the peptidoglycan sacculus, providing a multilayer thinsection profile. The five-layer cell envelope structure observed previously in thin sections of $C$. xylanolyticum cells (8) is actually a four-layer structure (the S layer, peptidoglycan, the inner $S$ layer, and cytoplasmic membrane) (Fig. 1a). However, some parts of the cell wall (8) appear to have only three layers and no inner $\mathrm{S}$ layer. This phenomenon has also been observed in other S-layer-containing bacteria, such as different Bacillus spp. $(14,15)$ or Clostridium spp. (13). Sometimes however, an erroneous conclusion has been drawn, namely, that a new cell wall architecture principle exists in those strains (14). It is obvious that the age of the culture plays an important role in the interpretation of the image obtained from thinly sectioned cells. An analysis of a great number of micrographs of freeze-etched preparations (5) of intact $C$. xylanolyticum cells by optical diffractometry (12) revealed that there is an oblique S-layer lattice $(a=6.6$ $\mathrm{nm} ; b=5.3 \mathrm{~nm} ; \gamma \sim 78^{\circ}$ ) which covers the bacteria completely (Fig. 1b). Sodium dodecyl sulfate-polyacrylamide gel electrophoresis of sodium dodecyl sulfate-solubilized whole cells (5) revealed a high-molecular-weight S-layer band (apparent $M_{\mathrm{r}}$, approximately 180,000) (Fig. 1c), which upon periodic acid-Schiff staining gave a weak but unambiguously positive staining reaction (data not shown). This observation indicates that an S-layer glycoprotein (6) is present on $C$. xylanolyticum cells. Additional studies will be necessary to determine the biological function and relevance of the glycosylated $S$ layer of $C$. xylanolyticum in the biodegradation of wood.

We thank Andrea Scheberl for excellent technical assistance.

Part of the work was supported by the Fonds zur Förderung der wissenschaftlichen Forschung in Österreich (project P7757).

\section{REFERENCES}

1. Beveridge, T. J., and J. A. Davies. 1983. Cellular responses of Bacillus subtilis and Escherichia coli to the Gram stain. J. Bacteriol. 156:846-858.

2. Buckmire, F. L. A. 1971. The physical structure of the cell wall as a differential character. Int. J. Syst. Bacteriol. 20:345-360.

3. Glauert, A. M., and M. J. Thornley. 1969. The topography of the bacterial cell wall. Annu. Rev. Microbiol. 23:159-198.

4. Hollaus, F., and U. B. Sleytr. 1972. On the taxonomy and fine structure of some hyperthermophilic saccharolytic clostridia. Arch. Mikrobiol. 86:129-146.

5. Messner, P., F. Hollaus, and U. B. Sleytr. 1984. Paracrystalline cell wall surface layers of different Bacillus stearothermophilus strains. Int. J. Syst. Bacteriol. 34:202-210.

6. Messner, P., and U. B. Sleytr. 1991. Bacterial surface layer glycoproteins. Glycobiology 1:545-551.

7. Messner, P., and U. B. Sleytr. 1992. Crystalline bacterial cellsurface layers. Adv. Microb. Physiol. 33:213-275.

8. Rogers, G. M., and A. A. W. Baecker. 1991. Clostridium xylanolyticum sp. nov., an anaerobic xylanolytic bacterium from decayed Pinus patula wood chips. Int. J. Syst. Bacteriol. 41:140-143.

9. Sleytr, U. B. 1978. Regular arrays of macromolecules on bacterial cell walls: structure, chemistry, assembly, and function. Int. Rev. Cytol. 53:1-64.

10. Sleytr, U. B., and A. M. Glauert. 1976. Ultrastructure of the cell walls of two closely related clostridia that possess different regular arrays of surface subunits. J. Bacteriol. 126:869-882.

11. Sleytr, U. B., and P. Messner. 1983. Crystalline surface layers on bacteria. Annu. Rev. Microbiol. 37:311-339.

12. Sleytr, U. B., P. Messner, and D. Pum. 1988. Analysis of crystalline bacterial surface layers by freeze-etching, metal shadowing, negative staining, and ultrathin sectioning. Methods Microbiol. 20:29-60.

13. Van Rijssel, M., and T. A. Hansen. 1989. Fermentation of pectin by a newly isolated Clostridium thermosaccharolyticum strain. FEMS Microbiol. Lett. 61:41-46.

14. Wahlberg, J., S. Tynkkynen, N. Taylor, J. Uotila, K. Kuusinen, M. Kuusinen, M. Häggblom, J. Viljanen, R. Villstedt, E.-L. Nurmiaho-Lassila, and K. Lounatmaa. 1987. A novel type of cell wall structure with two periodic layers (S-layer) of a Bacillus sp. strain KL1. FEMS Microbiol. Lett. 40:75-80.

15. Yamada, H., N. Tsukagoshi, and S. Udaka. 1981. Morphological alterations of cell wall concomitant with protein release in a protein-producing bacterium, Bacillus brevis 47. J. Bacteriol. 148:322-332. 